\title{
Emotional intelligence in South African women leaders in higher education
}

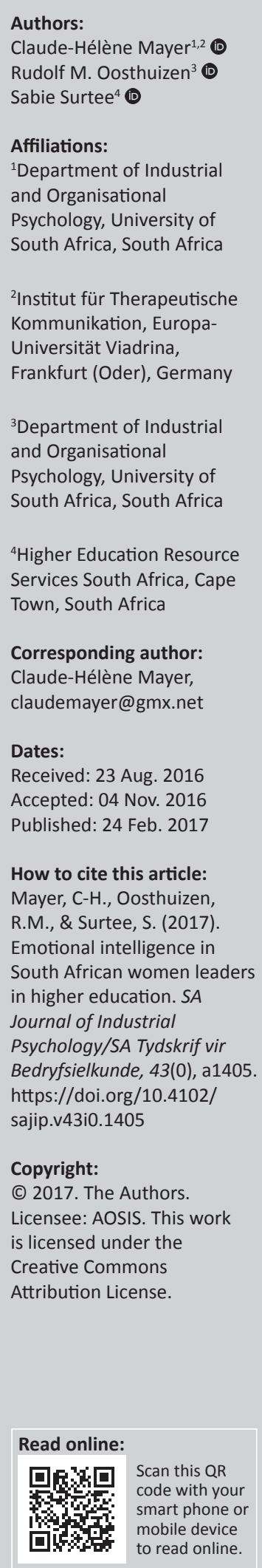

Orientation: This study contributes to an in-depth understanding of emotional intelligence (EI) in women leaders in Higher Education Institutions (HEIs) in South Africa from an inside perspective.

Research purpose: The purpose of this study is to explore EI in South African women leaders working in HEIs to identify women leader's strengths, foci and their possible areas of development. The aim is to get deeper insights in EI in women leaders because EI is associated with effective leadership qualities, creativity and innovation, as well as empathetic communication which is needed in the challenging HEI workplaces.

Motivation for the study: Emotional intelligence is an important source for women leaders to increase leadership qualities. This study is motivated by a deep interest to explore aspects of EI in women leaders in this specific professional context.

Research design, approach and method: The study uses a qualitative research design and an approach based on Dilthey's modern hermeneutics of 'Verstehen' (understanding). Twentythree women leaders of the Higher Education Research Service (HERS-SA) network were interviewed through semi-structured interviews. One researcher observed behaviour in one HEI to support the interpretation of the data. Data were analysed through content analysis.

Main findings: Findings show that women leaders mainly refer to intrapersonal emotional quotient (EQ), followed by interpersonal EQ, adaptability, stress management and, finally, general mood. The most highly rated components of EQ are self-regard, followed by interpersonal relationships, problem solving, empathy, emotional self-awareness, assertiveness, impulse control and social responsibility. Findings also provide ideas on what EQ components can be further developed.

Practical/managerial implications: New insights are provided on what components of EI should be developed in women leaders to increase overall EI, on cognitive and behavioural levels.

Contribution/value-add: This research provides new and original context-specific insights on EI in HEIs in South Africa, which can be used as a basis for future research on women leaders while providing a knowledge base for contemporary training of EI in HEIs.

\section{Introduction}

South African leaders and organisations are riddled by challenges of the post-apartheid era, such as radical changes in equity legislation, a call for a more gender-balanced and culturally diverse work force, as well as the need to stay globally competitive (Mayer, 2011; Oosthuizen \& Naidoo, 2010). The South African Constitution emphasises a non-racial and non-sexist democracy. However, complex societal and educational issues, ranging from social and gender inequalities (Teferra \& Altbach, 2004), experiences of discrimination, marginalisation and the exclusion of women in leadership positions challenge South African leaders in Higher Education Institutions (HEIs) (Du Plessis \& Barkhuizen, 2012; Lewis-Enright, Crafford \& Crous, 2009; Martin \& Barnard, 2013; Mayer \& Barnard, 2015). Research highlights the important role of women in leadership in the African context (Darkwah, 2007; Kinnear, 2014; Mayer, Surtee \& Barnard, 2015; Mayer \& Van Zyl, 2013) and women leaders in South Africa are acknowledged as holding a resonance-building leadership style, consisting of adaptive communication skills, mentoring abilities, collaboration and qualities of cooperation (Van Wyk, 2012).

Emotional intelligence (EI) and emotional quotient (EQ), which refers to the subscales of EI, play a pivotal role in leadership studies (Cavazotte, Moreno \& Hickmann, 2012; Du Toit, Viviers \& 
Mayer, 2016; Pillay, Viviers \& Mayer, 2013), particularly in the self-development of women. It occurs on the micro-level in observed and measured increases in the productivity, building positive relations and gaining emotional commitment from human capital. At the macro-level, this strengthens organisational culture, resilience and flexibility (Jonck \& Swanepoel, 2015). Furthermore, empathetic communication between women leaders and staff develop a culture of trust that increases synergy among employees, stimulating creativity and innovative responses to complex demands (Lazovic, 2012, p. 797). In this context, EI increases success in women leaders (Jonck \& Swanepoel, 2015) and EQ builds a base for increased leadership qualities in women (Anand \& Suriyan, 2010; Chaudhry \& Saif, 2012; Rahim \& Malik, 2010). Singh (2010) argues that organisations can enhance EI in women leaders by improving their competencies, namely, people success, system success and self-success. This can be done through training programmes to improve EI in women leaders (Grant, 2007), and EQ has been suggested as a recruitment tool for the South African organisational context (Jonker, 2009) because EI contributes to effective leadership (Chaudhry \& Saif, 2012).

The purpose of this study is to explore and understand EI in South African women leaders working in HEIs, aiming at new insights into EI from an emic women leadership perspective. The study contributes to an in-depth understanding of facets of EI in women leaders in HEIs, which builds the basis of coping with the challenges of leadership, as well as recommendation for future theory and practice. To respond to the aim of the study to explore EI in women leaders in South African HEIs, the main research question was posed: 'Which aspects of EQ are important to women leaders in South African HEIs?'

\section{Trends from the research literature The South African context}

Exploring and understanding gender in South African HEIs requires an understanding of the complexities generated by its socio-historical legacy (Mabokela \& Mawila, 2004). During apartheid, South Africans were classified as Africans, mixed races, Indians and whites (Healey \& O'Brien, 2015), whereby black women were defined as second-class citizens (Mabokela \& Mawila, 2004) carrying a double burden of sexism and racism (Wing \& De Carvalho, 1995, p. 57), with racial markers being contradictory and interrelated to gender and economic status (Mayer, 2011; Puttick, 2012). With the onset of the post-apartheid era in 1994 and the implementation of the Employment Equity (EE) Act (Department of Labour, 1998), Africans, mixed races and Indians were defined as black and categorised together with women and disabled people who became the designated groups and main focus of Affirmative Action Programmes (Booysen, 2007).

In contemporary South Africa, transformation processes and new interpretations of gender roles, concepts and dynamics are ongoing (Gouws, 2008; Mayer \& Barnard, 2015), and women are increasingly occupying management and executive management positions (Kinnear, 2014; Mostert, 2009). However, gender inequalities in South Africa still remain, as concepts of masculinity and femininity impact on leadership, management, communication and careers (Faulkner, 2009; Mayer et al., 2015). Employees need to respond to an increasing propensity for conflict and develop innovative strategies to manage conflict constructively (Mayer, 2008), through EI (Kelly \& Kaminskiené, 2016) and gender-sensitive training (Boyd, 2016).

\section{Emotional intelligence and the Bar-On model}

The concept of EI has been defined in many different ways with most of the definitions sharing selected theoretical underpinnings, such as awareness and understanding of one's own and others' emotions and the ability to manage one's own emotions and the emotions of others (Bar-On, 1997; Goleman, 1998; Grigoriou, Vasiliki, Tachias, Gilyana \& Bougiesi, 2012; Salovey \& Mayer, 1990). EI has been linked to various organisational variables such as positive work attitudes, behaviour and outcomes (Sinha \& Kumar, 2016). It has also been linked positively to leadership (Du Toit et al., 2016; Pillay et al., 2013) and job satisfaction (Kafetsios \& Zampetakis, 2008) to name but a few.

EI, as a broad construct addresses the emotional, personal, social and survival dimensions of intelligence (Stein \& Book, 2006, p. 16; Stein, Papadogiannis, Yip \& Sitarenios, 2009). However, there seem to be robust debates and lack of consensus around what exactly the definition of EI should comprise (Dulewicz \& Higgs, 2000). Bar-On's (1997, p. 14) non-cognitive model more generically referred to EI as 'an array of non-cognitive capabilities, competencies and skills that influence one's ability to succeed in coping with environmental demands and pressures' (Du Toit, 2014).

Bar-On (2002) refers to EI as a construct and suggests that there is significant overlap between many concepts involved in EI and he thus refers to it more generally as emotional and social intelligence (ESI). Darwin's early work on the importance of emotional expression for survival and adaptation (1872/1965) has influenced the ongoing development of the Bar-On model, which both stresses the importance of emotional expression and views the outcome of emotionally and socially intelligent behaviour in Darwinian terms of effective adaptation. Additional influence on this thinking can be traced to Thorndike's description of social intelligence and its importance for human performance (1920) and to Wechsler's observations relating to the impact of non-cognitive and cognitive factors on what he refers to as 'intelligent behaviour' (1940, 1943). Sifneos' description of alexithymia (1967) on the pathological end of the ESI continuum and Appelbaum's conceptualisation of psychological mindedness (1973) on the eupsychic end of this continuum have also impacted on the ongoing development of the Bar-On model (Bar-On, 2006; Ramesar, Koortzen \& Oosthuizen, 2009). 
From Darwin to the present, most descriptions, definitions and conceptualisations of EI include one or more of the following five key components: (1) the ability to recognise, understand and express emotions and feelings; (2) the ability to understand how others feel and to relate to them; (3) the ability to manage and control emotions; (4) the ability to manage change, adapt and solve problems of both a personal and an interpersonal nature; and (5) the ability to generate a positive affect and be self-motivated (Bar-On, 2006; Ramesar et al., 2009).

The Bar-On model provides the theoretical basis for the emotional quotient inventory (EQ-i) instrument, which was originally developed to assess various aspects of this construct and to examine its conceptualisation. According to this model, ESI is a cross-section of interrelated emotional and social competencies, skills and facilitators that determine how effectively we understand and express ourselves, understand others and relate to them and cope with daily demands (Yamani, Shahabi \& Haghani, 2014). The emotional and social competencies, skills and facilitators referred to in this conceptualisation include the five key components described above. Each of these components comprises a number of closely related competencies, skills and facilitators. Bar-On (1997) defines EI as an array of non-cognitive capabilities, competencies and skills. This model is converted into a table in Table 1 for ease of reference (Bar-On, 2000, p. 365).

A description of the EI model of Bar-On comprises five scales with 15 subscales. These are intrapersonal EQ, comprising self-regard, emotional awareness, assertiveness, independence and self-actualisation; interpersonal EQ, comprising empathy, social responsibility and interpersonal relationships; stress management EQ, comprising stress tolerance and impulse control; adaptability EQ, comprising reality testing, flexibility and problem solving; and general mood EQ, comprising optimism and happiness (Bar-On, 2000). The description of each of the scales is presented in Table 1. According to McCallum and Piper (2000), the model proposed by Bar-On is perhaps the clearest and most comprehensive to date (Ramesar et al., 2009).

According to McCallum and Piper (2000), the model proposed by Bar-On is perhaps the clearest and most comprehensive to date (Ramesar et al., 2009). Bar-On (2002) hypothesises that individuals with higher than average EI are more capable of meeting environmental demands and pressures. Furthermore, he proposes that a deficiency in EI can mean a lack of success and the existence of emotional problems. In general, he considers emotional and cognitive intelligence to contribute equally to a person's general intelligence, which suggests a likelihood of one's potential success in life (Bar-On, 2002). EI is an essential aspect in determining one's ability to succeed in life and is understood to directly influence one's state of mind or overall degree of emotional health (Bar-On, 1997). Based on these insights, Stuart and Paquet (2001, p. 30) postulate, 'emotional health should also have some impact on the presence or absence of leadership ability' (Du Toit, 2014).

\section{Research design \\ Research approach and strategy}

The study uses a qualitative research design based in a hermeneutical research paradigm, using Dilthey's (2002) modern hermeneutics of 'Verstehen' (understanding). A constructivistic research approach was used to explore EI within a context-specific setting (Patton, 2002). The study explores facets and components of EI, while the researchers apply a self-reflective attitude in interpreting the experiences

TABLE 1: Emotional intelligence model.

\begin{tabular}{|c|c|}
\hline Scale & Description of the scale \\
\hline \multicolumn{2}{|l|}{ Intrapersonal EQ } \\
\hline Self-regard (SR) & Is the ability to be aware of, understand, accept and respect oneself \\
\hline Emotional self-awareness (ES) & Is the ability to recognise and understand one's emotions \\
\hline Assertiveness (AS) & Is the ability to express feelings, beliefs and thoughts and to defend one's rights in a non-destructive manner \\
\hline Independence (IN) & Is the ability to be self-directed and self-controlled in one's thinking and actions and to be free of emotional dependency \\
\hline Self-actualisation (SA) & Is the ability to realise one's potential and to do what one wants to do, enjoys doing and can do \\
\hline \multicolumn{2}{|l|}{ Interpersonal EQ } \\
\hline Empathy (EM) & Is the ability to be aware of, understand and appreciate the feelings of others \\
\hline Social responsibility (RE) & Is the ability to demonstrate oneself as a cooperative, contributing and constructive member of one's social group \\
\hline Interpersonal relationship (IR) & $\begin{array}{l}\text { Is the ability to establish and maintain mutually satisfying relationships that are characterised by emotional closeness, intimacy and giving and } \\
\text { receiving affection }\end{array}$ \\
\hline \multicolumn{2}{|l|}{ Stress management EQ } \\
\hline Stress tolerance (ST) & Is the ability to withstand adverse events, stressful situations and strong emotions without 'falling apart' by actively and positively coping with stress \\
\hline Impulse control (IC) & Is the ability to resist or delay an impulse, drive or temptation to act and to control one's emotions \\
\hline Adaptability EQ & \\
\hline Flexibility (FL) & Is the ability to adjust one's feelings, thoughts and behaviour to changing situations and conditions \\
\hline Problem solving (PS) & Is the ability to identify and define personal and social problems and to generate and implement potentially effective solutions \\
\hline \multicolumn{2}{|l|}{ General mood EQ } \\
\hline Optimism (OP) & Is the ability to 'look on the brighter side of life' and to maintain a positive attitude, even in the face of adversity \\
\hline Happiness (HA) & Is the ability to feel satisfied with one's life, to enjoy oneself and others, to have fun and express positive emotions \\
\hline
\end{tabular}

El stands for emotional intelligence, EQ means emotional quotient and refers to the subscales, which form the concept of El, as referred to in Table 1.

Source: Bar-On, R. (1997). The emotional intelligence inventory (EQ-i): Technical manual. Toronto: Multi-Health Systems 
in narrations (Ratner, 2002), viewing research as being subjective, social-culturally constructed with contextual meanings (Ellingson, 2013). Thus, research integrates the interpreting of ideas, purposes and other experiences regarding EI expressed in the emic, subjective reality (Dilthey, 2002/1910) of the participants.

\section{Research method}

\section{Research setting and sample}

Higher Education Research Service (HERS-SA) is a non-profit organisation, which promotes and advances the leadership development and representation of women in HEIs in South Africa. The study was conducted involving 23 participants working at eight HEIs in South Africa.

Women leaders from the HERS-SA network were contacted to voluntarily participate in the research project. Researcher roles were established through personal introduction before the interviews took place. Convenience and snowball sampling was implemented. All participants are South African citizens who work in leadership positions in academia (e.g. head of department) or in administration (e.g. director). The sample comprised women leaders from four race groups as defined in the EE Act of 1998.

\section{Data collection}

Data were collected through semi-structured interviews, 16 face-to-face and 7 Skype interviews, in eight South African HEIs. Two researchers were involved in the interviews, one researcher conducted participant observation in one HEI. Data were collected in 2014 and 2015. Field notes from the observations were used to interpret the data. Semi-structured interviews used questions such as 'Please explain how you experience your work situation?', 'How do you feel working in HEI as a women leader?', 'How do you manage stress?', 'How do you respect yourself and others?'. Interviews were recorded and transcribed verbatim. Data were recorded on a technical recording device, transcribed verbatim and stored on a PC.

\section{Data analyses}

Content analysis and observations are used (Vaismoradi, Turunen \& Bondas, 2013) to analyse the data, applying the five-step process of content analysis according to Terre Blanche, Durrheim and Kelly (2006, pp. 322-326). With regard to coding, abductive coding procedures were used (Mayer, 2011). The steps of content analysis included step 1 - familiarisation and immersion; step 2 - inducing themes; step 3 - coding; step 4-elaboration; and step 5-interpretation and checking (Terre Blanche et al., 2006, pp. 322-326; Vaismoradi, Jones, Turunen \& Snelgrove, 2016).

During the data analysis process, interpersonal validation processes (Yin, 2009) between the researchers were applied to re-evaluate and reconstruct the data (Terre Blanche et al., 2006). Discussions and sessions of reflections were held during the processes of data collection and analysis among the researchers. Findings are reported in a qualitative reporting style.

\section{Ethical considerations and research criteria}

Ethical approval was provided by Rhodes University in Grahamstown, South Africa, while the participants who were assured of anonymity, confidentiality and voluntarily participation gave individual informed consent. Ethical considerations included the respect afforded to participants and their rights, informed consent, confidentiality, anonymity and transparency. As the study was conducted within a hermeneutical paradigm, the concepts of validity and reliability were defined in terms of qualitative research criteria, such as credibility, transferability and dependability (Lincoln \& Guba, 1985). Credibility was established through the research design, the interviewees, the researcher and the context (Poggenpoel, 1998). With regard to transferability, the study used interpretative research approaches and the constructionist assumptions that meanings are highly variable across the context of human interaction and, therefore, does not seek generalisable findings (Mayer, 2011). Research conclusions were generalised only with regard to the context of conduct. Dependability is achieved through rich and detailed descriptions of the research methodology employed for data collection and analysis (Van der Riet \& Durrheim, 2008).

\section{Findings}

Twenty-three women from all four race groups participated voluntarily and provided rich data on EI (see Table 2). Data saturation was reached.

\section{Emotional intelligence in women leaders}

The findings below show how women leaders address EI with regard to intrapersonal, interpersonal EQ, stress management, adaptability and general mood (see Tables 3, 4 and 5).

Aspects in the realm of intrapersonal EQ are emphasised in terms of total statements by the participants.

\begin{tabular}{lccc}
\hline TABLE 2: Biographical data. & Total & $\begin{array}{c}\text { Academic conditions } \\
\text { of service }\end{array}$ & $\begin{array}{c}\text { Administrative or } \\
\text { support services }\end{array}$ \\
\hline African (A) & 3 & 1 & 2 \\
mixed race (C) & 5 & 3 & 2 \\
Indian (I) & 4 & 4 & 0 \\
white (W) & 11 & 5 & 6 \\
\hline Total & $\mathbf{2 3}$ & $\mathbf{1 3}$ & $\mathbf{1 0}$ \\
\hline
\end{tabular}

TABLE 3: Stress management.

\begin{tabular}{|c|c|c|c|c|c|}
\hline $\begin{array}{l}\text { Stress management } \\
\text { EQ }\end{array}$ & African & $\begin{array}{l}\text { Mixed } \\
\text { race }\end{array}$ & Indian & White & Total \\
\hline Stress tolerance & - & - & 122 & W7, W14, W16 & 4 \\
\hline Impulse control & A29 & $\begin{array}{l}\text { C13, C23, } \\
\text { C19S }\end{array}$ & $\begin{array}{l}19,118 \\
122\end{array}$ & $\begin{array}{l}\text { W7, W14, W16, } \\
\text { W27, W5S, W6S, } \\
\text { W11S, W20S }\end{array}$ & 15 \\
\hline
\end{tabular}

$E Q$, emotional quotient. 
TABLE 4: Adaptability.

\begin{tabular}{|c|c|c|c|c|c|}
\hline Adaptability & African & Mixed race & Indian & White & Total \\
\hline Reality testing & - & C13 & $19,117,122$ & W2S, W7, W15 & 7 \\
\hline Flexibility & $\mathrm{A} 12, \mathrm{~A} 21$ & - & 19 & W7 & 4 \\
\hline $\begin{array}{l}\text { Problem } \\
\text { solving }\end{array}$ & $\begin{array}{l}\text { A12, A21, } \\
\text { A29 }\end{array}$ & $\begin{array}{l}\text { C13, C23, } \\
\text { C28, C19S }\end{array}$ & 19,117 & $\begin{array}{l}\text { W2S, W7, W14, } \\
\text { W15, W16, W3S, } \\
\text { W5S, W6S, } \\
\text { W11s, W26S }\end{array}$ & 19 \\
\hline Total & - & - & - & - & 30 \\
\hline
\end{tabular}

TABLE 5: General mood.

\begin{tabular}{lllclc}
\hline General mood & Black & Mixed race & Indian & White & Total \\
\hline Optimism & B12 & C13 & 19 & W7, W14, W16, W6S & 7 \\
Happiness & - & C23 & 122 & W15, W26S & 4 \\
\hline Total & - & - & - & - & 11 \\
\hline
\end{tabular}

\section{Self-regard}

With 22 statements on self-regard, women leaders highlight that self-regard is majorly important. One notes:

It's mainly about a deeper understanding of who you are really, and that's why I'm saying you have to tap into your soul, because it's not superficial. [A29, female]

A29 is of the opinion that working with others successfully requires a high level of self-regard and an in-depth understanding. One points out:

'You have to be true to yourself and true to what you are doing'. [I18, female]

Here, a deeper level of truth and honesty are required, building on a basis of self-regard. Further on, truth based on different levels of the individual provides the basis for authenticity and effective leadership. Comments on selfregard generally include a deeper understanding and recognition of the person that builds the basis for working with others (A29, I18).

\section{Emotional self-awareness}

Sixteen comments across racial groups refer to emotional self-awareness, emphasising:

'We women cannot separate ourselves from our emotions, and the things that happen to us ...' [B21, female]

The understanding that women and emotions build a unit leads to the assumption that women should be aware of their emotions in order to deal with them effectively. One explains strategies of dealing with emotional awareness and, particularly 'negative' experienced emotions, which are connected to injustice and discrimination:

'One mustn't let the sun set on your anger. So I try very hard to make that the case. It's very difficult because I have a great capacity for passion and anger - injustice really angers me.' [C9, female]

Another also mentions anger:

'I have lots of anger. When I sit in a meeting, and I just know, this is not the way to go. I'll give you an example. If I know I am not empowered enough to do anything about it, then I become angry and the consequence is that I ignore it when I know it is not good.' [I18, female]
Several black women refer to anger, experiencing feelings of inferiority, discrimination, disempowerment or injustice and are aware that they need to deal with these feelings, which are a challenge. Ignorance towards anger is one strategy to deal with emotions. Furthermore, emotional awareness is important to participants in terms of experiencing, understanding and consciously developing deeper awareness. According to this study, such a valuable emotional awareness then introduces a positive personal behavioural change and healthy leadership behaviour by women leaders.

\section{Assertiveness}

Assertiveness, the ability to express feelings, beliefs and thoughts to defend one's rights in a non-destructive manner, is important for women leaders (Bar-On, 2006) (15 comments). Most of the statements show that women leaders are assertive about expressing feelings, beliefs and thoughts and defend their rights, because of the fact that they often feel discriminated as explained above. They feel that they need to express themselves - even in a more non-destructive or selfdestructive manner, as they do. Providing a good example how she deals with assertiveness, as follows:

'I've got a few staff members that report to me. The way I have actually dealt with them is, I treat them with absolute respect, I trust them to be professional in class and I give them all the support they need. I express my feelings and need to know what they belief, feel and think.' [A21, female]

A21 aims at relating to her staff through connecting on a feeling-level while exploring their beliefs, feelings and thoughts to get to know them as human beings, including their individual core. For C9, however, being assertive also means 'being mindful', and for her, 'being mindful is about being conscious'. Several women highlight assertiveness; however, they also note at the same time a 'lack of assertiveness' in themselves and within their work environment: I22, for example, describes that in a conflict with her colleagues, she was not able to express her feelings and thoughts and finally 'exploded' and 'left her job'. Assertiveness is an extraordinarily important quality in conflict management in the context of gendered discrimination, as I17 points out. It helps to express oneself non-violently and non-destructively.

\section{Independence}

With only four comments, independence, as an aspect of intrapersonal EQ, is desired, but hardly experienced by women leaders. C13 prioritises to decide on topics and work issues independently: 'I would do it in terms of priority, what interests me most and how it links to my professional career'. However, she realises during the interview that she does not make decisions independently, although she would like to.

This might be related to the fact that women leaders seem to be insecure and experience their work environment as 'poisonous' or even 'hostile', impacting negatively on mental health and well-being: 
'If you are in a very toxic, poisonous environment you need to ask yourself, 'what are you getting out of it if it's that toxic for you?' If you're not getting anything out of it maybe you should think about leaving and going someplace else. If you are getting something out of it, is it worth it for you to put up with the toxic environment? So those are the types of negotiations we have to undertake and the kind of decisions we have to make but at the end of the day, I think it's very important for each of us to decide whether what we are doing, or the space we are in, is healthy for us or not -we have to make these decisions while being emotionally independent.' [I17, female]

Generally, women leaders in this study do not feel independent at work and are rather involved in a network of decision-making processes, while negotiating interpersonal relationships and gendered stereotypes.

\section{Self-actualisation}

Self-actualisation, as an aspect of intrapersonal EQ has only been mentioned in three instances throughout the data. W15, for example, highlights that her work in HE provides her with the ability to self-actualise and grow: 'My work gives me some self-actualisation, a growing experience and the opportunity to attend high-level meetings'. She self-actualises through tackling new challenges and meeting 'high level people', which provide her with new information, engage with her in new projects and value her ideas and thoughts and positive feelings regarding her career.

C19S also comments on self-actualisation. She experiences HEIs as lacking stimulation for women leaders' identity development: 'I prefer growth in terms of who I am and what I do. I think part of my discomfort in the workplace is that I become easily bored'. As Table 6 shows, women leaders frequently mention intrapersonal EQ as a very important aspect of work. Interpersonal EQ follows in importance, including empathy (18 comments), social responsibility (14 comments) and interpersonal relationships (21 comments) (Table 7).

\section{Empathy}

Women leaders rank empathy relatively high at work, being mentioned by all African and mixed race, by three quarters of Indian and seven out of 11 white leaders. One highlights:

'I regard myself as a very humble person. I care a lot about people. I'm a people's person - I care a lot about how people feel and how I come across to people so that they know ... I reach out to people.' [A12, female]
Caring and empathy are strongly related to positive selfevaluation and several women leaders seem to value others and a positive relationship to them. W14 describes her development within her career, turning towards empathy: 'I'm a far more empathetic leader now than I used to be. I'm more humble than I used to be'. W27 also values empathy: 'I am mindful to people's emotions, how they feel'. W11S finally emphasises: 'I do have empathy, definitely'. Empathy is valued by all women leaders as a very positive quality that they aim to reach or maintain. They also value empathetic communication of other towards them.

\section{Social responsibility}

As with empathy, most African, mixed race and Indian women leaders refer to social responsibility as indicating a cooperative and constructive membership of one's social group. For example, one describes her personal value of integrity based on social responsibility towards her department:

'I'm leading responsibly ... and with integrity. I think that's the most important thing. Always telling the truth, always making sure that one acts in the best interests of the group.' [C9, female]

Women leaders are of the opinion that leadership needs to imply 'acting responsibly' (C9) and this can be expressed in various ways, such as in 'challenging the status quo of individuals, through nurturing or caring' (C19S).

\section{Interpersonal relationships}

The most referred to aspect in interpersonal EQ is interpersonal relationships. Almost all participants independent of racial group belonging or academic or administrative positions emphasise that the ability to establish mutual interpersonal relationships with students, colleagues, superiors or subordinates is of highest importance to work successfully in HEIs. Interpersonal relationships need to be based on emotional closeness, intimacy and affection to have good, constructive and effective relationships. One points out:

'I'm loyal, very honest, and if there's one thing I know ... I do respect my students, I try to respect my colleagues as well and I build relationships. At the same time, I feel close to them. The things I value, I try to live by.' [A21, female]

Interpersonal relationships within the family and at work play an important role in the life of women leaders in this study and influence each other. Managing relationships is according to participants (e.g. W15, I9) strongly connected

TABLE 6: Intrapersonal EQ.

\begin{tabular}{|c|c|c|c|c|c|}
\hline Intrapersonal EQ & African & Mixed race & Indian & White & Total \\
\hline Self-regard & $A 12^{a}, A 21, A 29$ & $\mathrm{C} 9, \mathrm{C} 13, \mathrm{C} 23, \mathrm{C} 28, \mathrm{C} 19 \mathrm{~S}$ & $19,117,118,122$ & W2S, W7, W14, W15, W16, W27, W10S, W11S, W20S, W26S & 22 \\
\hline Emotional self-awareness & $\mathrm{A} 21, \mathrm{~A} 29$ & $\mathrm{C} 9, \mathrm{C} 13, \mathrm{C} 23, \mathrm{C} 28$ & $117,118,122$ & W7, W14, W15, W16, W10S, W11S, W26S & 16 \\
\hline Assertiveness & $\mathrm{A} 12, \mathrm{~A} 21$ & $\mathrm{C} 9, \mathrm{C} 13, \mathrm{C} 23, \mathrm{C} 28$ & 117 & W2S, W7, W14, W16, W5S, W10S, W20S, W26S & 15 \\
\hline Independence & - & C13 & 117 & W7, W14 & 4 \\
\hline Self-actualisation & - & C19S & & W7, W15 & 3 \\
\hline Total & & & & & 60 \\
\hline
\end{tabular}

aA12, African person, interview number 12; I, Indian, C, mixed race; W, white; S, Support staff (Management, Non-academic personnel staff). 
TABLE 7: Interpersonal EQ.

\begin{tabular}{lllll}
\hline Interpersonal EQ & African & Mixed race & Indian & White \\
\hline Empathy & A12, A21, A29 & C9, C13, C23, C28, C19S & 19, I18, I22 & W14, W15, W27, W3S, W6S, W11S, W26S \\
Social responsibility & A12, A21 & C9, C23, C28, C19S & I9, I18, I22 & W7, W14, W16, W10S, W20S \\
Interpersonal relationships & A12, A21, A29 & C9, C13, C23, C28, C19S & I9, I18, I22 & W7, W14, W15, W16, W27, W5S, W6S, W11S, \\
\hline Total & - & - & - & W20S, W26S \\
\hline
\end{tabular}

$E Q$, emotional quotient.

to mental health, (positive) thoughts and adequate actions and is:

'directly connected to ones core values'. [W15, female]

\section{Stress tolerance}

Further on, African and mixed race participants are not aware of stress and stress tolerance because comments on those topics are completely absent. Instead, these leaders positively describe how they manage challenging situations through spirituality, definitely an important health research. Only one Indian woman leader speaks about 'stress at work', but she also refers immediately to her coping mechanism 'spirituality':

'It's easy to feel stressed or overwhelmed with life. Spirituality gives me that focus and perspective and reminds me of what's important in life. Ultimately, it's not about getting the money, fame or whatever, it's about being happy in what I'm doing and it needs to contribute to some overall good.' [I22, female]

Besides these comments, three white participants speak about 'stress' and how to deal with it. W16 ascribes her ability to manage stress to her 'right personality': 'I have the personality that generally copes with it, copes with this sort of stress and tensions'. One describes, in contrast, her strong family support system to manage work stress as a HR leader:

'If struggle at work, life is not good at home, because there's a lot of stressors and tension being in a senior position, Human resources (HR) is very stressful. I find I'm less able to cope if I feel like things are not strong at home, because that's really my faith haven. If that's not going well, it definitely has an impact on my work. I think women are far more impacted because generally we are the home makers and we carry the burden of running stuff at home so we really are juggling quite a lot.' [W14, female]

\section{Impulse control}

With regard to the stress management control EQ, the findings show that women leaders have learned across all groups how to manage to control their emotional impulses and cope with their emotions effectively.

B29, for example, suppresses her feelings to control herself: 'You see I'm able to be moved from one direction to another as opposed to really being affected by it'. One provides a metaphoric expression of control impulses connected to discrimination:

'I have definitely experienced discrimination and you have to read the situation. You can't just come in with guns blazing wanting to transform and wanting gender rights. You have to tread very carefully, because if you are too outspoken about it you will be victimised left right and centre.' [I9, female]
Impulse control is a way to protect her (I9) within the working environment. I18 differentiates emphasises how balanced her impulse control should be to work effectively: 'Sometimes you must know when to keep quiet, and when to say certain things'. By contrast, one points out that impulse control is not always healthy, particularly, when it leads into inner withdrawal and suppression of emotions:

'I think it has been very damaging to myself and my own psychological health that I tend to retreat into myself I withdraw, yes. I think I try to find solace in my work basically, doing tasks rather than confronting people, so I'm very much a classical conflict-avoider, by controlling myself.' [C23, female]

Other participants note: 'I have learned to never respond to anything spontaneously' (W5S). W6S agrees that 'you have to be very diplomatic in HE', while W11S describes her strategy to control her impulses: 'I think lower your voice, don't get emotional ... finding a way to keep calm is very important'. W20S presents her protection mechanisms: 'I will protect myself from my tendency to become over-emotional by responding to requests via email, so that I've got time to reflect and choose my words carefully'. Finally, W27 concludes: 'You have to be careful in the way you word things so that you don't upset someone else'.

These statements indicate that participants feel they have to protect and control their impulses and emotions so as not to get into problems, be attacked or anger others. This means that women leaders aim at emotional harmony and selfprotection and feel that expressed emotions might impact negatively on them or their work.

With regard to adaptability, participants do not focus much on reality testing ( 7 comments) and flexibility (4 comments), but a relatively high amount of comments refer to problem solving (19 comments).

\section{Reality testing}

Reality testing refers to the ability to assess the correspondence between what is experienced internally and subjectively and what exists externally and objectively. African women do not acknowledge this concept at all, while the other women do, but to a small extent. One notes:

'Sometimes you have to be firm, so your leadership style has to be situational. You can't always be light-headed because people will not take you seriously and the work may not get done, so according to the situation and the reality around you, you have to adapt your leadership style to that situation.' [I9, female] 
This woman leader describes how she adapts her leadership style and her inner thoughts situationally and contextually, while assessing her 'intrapersonal and subjective' and her 'external and objective experiences', comparing and testing them.

\section{Flexibility}

Only four women speak about flexibility at work. One highlights flexibility in terms of switching between her work and family life and the roles she has to take on. She explains that the focus of her attention and awareness shifts flexibly according to the demands of her environment:

'The centre of focus between my various functions in life. Sometimes the focus is going to be more on the family, sometimes more on the career and sometimes more on other things. It is work, family and career. Every now and then the focus shifts ... Then, I go with the flow and adjust flexibly to the needs.' [A21, female]

A21 views flexibility as the need of contextual adjustment and the setting someone works in. To survive in HEIs, the described flexibility is needed in combination with selfawareness. In contrast, I9 and I22 refer to adaptability in terms of practical problem solving skills they apply at work.

\section{Problem solving}

In the context of adaptability, problem solving is a highly ranked concept for women leaders. One mixed race participant refers to practical skills:

'I think one needs to do conflict management, because sometimes a conflict situation could be quite energising, it makes you think differently, makes you confront issues that may be in your blind spot, but you are not able to see them. So, I don't think all conflict is necessarily negative. It may be uncomfortable and difficult to deal with, but it may not be negative.' [C28, female]

Several participants note that problem solving is part of their work routine, which they generally do not enjoy. However, women leaders see conflict management as a necessity to implement positive change within the organisation. This is particularly true for women leaders in administration and might be influenced by the fact that their work time is mainly dominated by communicative and conflict management issues.

Finally, with regard to general mood, only seven women leaders refer to 'optimism' in life and careers, while even fewer women (four) mention happiness. Women leaders are aware of their emotions with regard to specific situations, as shown above; however, they do not reflect much on their general mood, only in the context of their coping strategies, such as spirituality and spiritual coping mechanisms.

\section{Optimism}

An Indian participant highlights (I9): 'Just smile a lot, be optimistic', while a white woman leader emphasises: 'Every day you hope it gets a bit better'. When coping with challenges at work and points out:

'I try to approach life with a positive attitude - I think I'm a realist. I try to deal with situations as they are, but very often - if I'm unhappy - I will sit down and try to think things through.' [W7, female]

For W7, optimism is related to a positive attitude, self-reflexive behaviour, the analysis of unhappiness and the ability to turn negative experiences into positive experiences. Optimism thereby becomes a strategy to deal with all the negative experiences women leaders encounter.

'Be optimistic, I think it helps me to remain calm. I think, things may be bad now, but they won't always remain like that and you've got to actually do something to change it. Or if things go bad and you can't change anything, you have to give yourself time to get over it and not beat yourself up about it, and then move on.' [C13, female]

As a coping mechanism, optimism helps women leaders to deal with their challenges and stay healthy.

\section{Happiness}

Only a few women speak about happiness and leadership, which shows that they do not experience the workplace as pleasant. Only after having left HEIs, the participant notes:

'I just felt I had enough and I left. I feel much happier now, have a better sense of direction, and I'm much more fulfilled now that I'm in charge of what's happening to me. I can decide what kind of situations I'd put myself into and what I choose not to put myself into.' [I22, female]

For I22, happiness is connected to independent decisionmaking, freedom of decision-making and self-efficacy. She feels happy having left her previous employment in HEI by giver herself self-direction. A white participant is happy with her work in HEI:

'I enjoy life. I am enjoying my work.' [W15, female]

One participant points out that happiness is based on good social relationships:

'I feel happy when everybody else around me is happy. It's very meaningful and I think I have achieved it.' [W26S, female]

Finally, a mixed race leader refers to happiness as being connected to age and increased feelings of participation and spirituality:

'I used to be very career-driven. A lot of my identity was shaped by excelling academically, but as I grow older, I pay more attention to my own spiritual needs - what I need to be happy and what I need to feel fulfilled. I try construct a community for myself, so that I feel part of something that's bigger than me and my own needs and wants.' [C23, female]

Happiness for women leaders is rather connected to self-direction, self-determination, meaningfulness at work, positive interpersonal relationships and spiritual selfdevelopment. 
Table 8 provides an overall view on the frequency of women leaders' statements on EQ.

In the following section, the findings of the study will be discussed in terms of the literature reviewed.

\section{Discussion}

This study supports previous research referring to conflictriddled organisations and post-apartheid challenges, taking gender and diversity factors into account (Mayer, 2011; Oosthuizen \& Naidoo, 2010). Participants speak about their experiences in terms of gender inequalities (as in Teferra \& Altbach, 2004), discriminative experiences and marginalisation and exclusion as emphasised previously (Du Plessis \& Barkuizen, 2012; Lewis-Enright et al., 2009; Martin \& Barnard, 2013; Mayer \& Barnard, 2015). This study supports the insight (Darkwah, 2007; Kinnear, 2014; Mayer \& Van Zyl, 2013; Mayer et al., 2015) that women leadership plays a pivotal role in South African leadership. They aim at high-quality professional leadership (Van Wyk, 2012) by applying EQ aspects (Cavazotte et al., 2012; Du Toit et al., 2016; Pillay et al., 2013). This research responds to Andries's (2009) request to understand and improve women leaders' EI to then improve their success). Based on the research, experience of EQ is a key concept for women leaders in HEIs in terms of self-understanding and understanding others (Bar-On, 1997; Goleman, 1998; Grigoriou et al., 2012; Salovey \& Mayer, 1990). Intrapersonal EQ (60 statements) is most frequently mentioned and followed by interpersonal EQ (53 statements) and adaptability (30 statements).

Women leaders experience gender inequalities (as in Gouws, 2008; Mayer \& Barnard, 2015). Findings provided evidence

TABLE 8: Overall statements on EQ in women leaders in HEls.

\begin{tabular}{|c|c|c|c|c|c|}
\hline Variable & African & Mixed race & Indian & White & Total \\
\hline \multicolumn{6}{|l|}{ Intrapersonal EQ } \\
\hline Self-regard & 3 & 5 & 4 & 10 & 22 \\
\hline Emotional self-awareness & 2 & 4 & 3 & 7 & 16 \\
\hline Assertiveness & 2 & 4 & 1 & 8 & 15 \\
\hline Independence & - & 1 & 1 & 2 & 4 \\
\hline Self-actualisation & - & 1 & - & 2 & 3 \\
\hline \multicolumn{6}{|l|}{ Interpersonal EQ } \\
\hline Empathy & 3 & 5 & 3 & 7 & 18 \\
\hline Social responsibility & 2 & 4 & 3 & 5 & 14 \\
\hline Interpersonal relationships & 3 & 5 & 3 & 10 & 21 \\
\hline Total & & & & & 53 \\
\hline \multicolumn{6}{|l|}{ Stress management EQ } \\
\hline Stress tolerance & - & - & 1 & 3 & 4 \\
\hline Impulse control & 1 & 3 & 3 & 8 & 15 \\
\hline Total & & & & & 19 \\
\hline \multicolumn{6}{|l|}{ Adaptability EQ } \\
\hline Reality testing & - & 1 & 3 & 3 & 7 \\
\hline Flexibility & 2 & - & 1 & 1 & 4 \\
\hline Problem solving & 3 & 4 & 2 & 10 & 19 \\
\hline Total & & & & & 30 \\
\hline \multicolumn{6}{|l|}{ General mood EQ } \\
\hline Optimism & 1 & 1 & 1 & 4 & 7 \\
\hline Happiness & - & 1 & 1 & 2 & 4 \\
\hline Total & & & & & 11 \\
\hline
\end{tabular}

EQ, emotional quotient; $\mathrm{HEI}$, higher education institutions. that self-regard is a core of professional leadership and interpersonal cooperation. Furthermore, emotional awareness is strongly valued by women leaders in terms of emotional awareness and behavioural awareness, referring to healthy self-development in which productivity, building positive relations and gaining emotional commitment form the human capital. This strengthens organisational culture, resilience and flexibility at the macro-level (as in Jonck \& Swanepoel, 2015). Findings support previous studies regarding empathetic communication and trust, increasing synergy among employees, stimulating creativity and innovative responses to complex demands (Lazovic, 2012, p. 797). Research by Stuart and Paquet (2001) and Du Toit (2014) postulate the connection of emotional health and leadership ability, which is supported by the findings which show that happiness and optimism are used as coping mechanism and that negative experienced emotional health is associated with rather destructive behaviour and anger.

On the one hand, women leaders are assertive about expressing feelings, beliefs and thoughts to defend their rights, and on the other hand, they aim at non-destructive or non-self-destructive manner. Independence, as an aspect of intrapersonal EQ does not seem to be outstandingly important for women leaders in HEIs. This shows that women leaders are very sensitive with regard to constructive individual work behaviour and relationships and that they are very aware of how to express their feelings, thoughts and beliefs in a constructive manner. Self-actualisation scores lowest in women leaders with regard to intrapersonal EQ. This might be because of the fact that women leaders already feel that they self-actualise through their work context a lot (as mentioned by one participant W15) and that is why they do not focus on this intrapersonal EQ aspect as much as on others.

This study's findings suggest that interpersonal EQ follows intrapersonal EQ in importance because women leaders value interpersonal relationships and therefore emphasise interpersonal EQ in terms of emotional closeness, intimacy and affection to create good, constructive and effective relationships. Empathy is ranked relatively high as an EQ aspect in the life and work of women leaders, supporting previous insight by Lazovic (2012) and Jonck and Swanepoel (2015) that empathy is needed to responding to complex work demands adequately. Empathy and social responsibility of the individual woman leader are highlighted, which expresses the values of caring and nurturing and empathetic understanding and the wish for constructive work relationships.

With regard to differences in race, the data show that African participants mainly highlight self-regard, empathy, interpersonal relationships and problem solving, while mixed race leaders focus on self-regard, empathy and interpersonal awareness, followed by emotional awareness, assertiveness, problem solving and social responsibility. Indian leaders focus on self-regard, emotional awareness, 
empathy, social responsibility, interpersonal relationships, impulse control and reality testing, while white leaders emphasise self-regard, interpersonal relationships and problem solving. These three concepts are followed by assertiveness and impulse control. The differences in favouring EQ foci of women leaders with differences in group membership are relatively small, but need further attention in future research. Four out of 11 white interviewees focus on optimism, which might be because of the changing South African HEI work environment in terms of Black Economic Empowerment (BEE), which prioritises the advancement of black staff in terms of the Employment Equity Act. Optimism might be a (maybe even unconscious) strategy to adjust to the organisational structural and diversity-related changes.

African and mixed race women did not comment on stress and stress tolerance, but only one Indian woman mentioned stress in the context of coping with it on a spiritual level. Three white women refer to stress and how to deal with it, which might show that they are mostly prone to stress which might again be related to societal and organisational changes. With regard to the stress management and controlling EQ, women in general have learned to manage their (emotional) impulse control to cope with their emotions. They emphasise that they are not being judged as (overly) emotional. Bar-On (2002) hypothesises that those individuals with higher than average EQ's are better able to meet environmental demands and pressures and therefore adjust strongly with regard to impulse control in their work environment.

Regarding adaptability, as part of EQ, women leaders hardly refer to the importance to reality testing in their work lives. African women do not refer to this concept at all, while women of the other groups do to a small extent. A white woman refers to flexibility with regard to the contextual adjustment and the work setting. It also relates to being flexible to self-awareness and a broader EQ. However, women leaders see problem solving as a main part of their job description and in that aspect, they have to deal with conflict on a daily basis (Mayer, 2008). Problem solving is a highly referred to EQ aspect (Kelly \& Kaminskiené, 2016) for all women leaders, which they describe as one of the major challenges at work. Seven women refer to optimism as an important aspect in their life and careers, while only four women refer to happiness. Findings show that women leaders across all groups seem to be occupied with their mood regarding specific events, but not with regard to general mood. If changes and challenges occur, women leaders use optimism (partly connected to spirituality) as a coping strategy, particularly in case they do feel that structural changes occur which they can hardly influence.

As referred to in previous research, EQ is an essential aspect in determining one's ability to succeed in life and is understood to directly influence one's state of mind or overall degree of emotional health (Bar-On, 1997).
Findings of this study support previous research on EQ that women leaders draw on EQ concepts to maintain or become emotionally healthy. Women in this study point out that they feel happy and healthy when they experience their abilities to deal with individuals and situations in a constructive and effective way. This connects to the findings of Anand and Suriyan (2010) and Chaudhry and Saif (2012) who relate leadership qualities and EQ. Although this study does not directly connect leadership qualities and EQ, women leaders highlight that they feel more self-assured and positive when they experience a high self-regard and strong intrapersonal and interpersonal qualities, which help them to lead according to their ideals. This might be connected to leadership qualities, but needs further research to be established.

\section{Conclusion}

This study responds to the research question of which aspects of EQ are important to women leaders in South African HEIs and thereby contributes to a deeper understanding of this issue from the methodological stance of Dilthey's modern hermeneutics of 'Verstehen'. Findings indicate that women mainly refer to intrapersonal EQ, followed by interpersonal $\mathrm{EQ}$, adaptability, stress management and finally general mood. Findings show that the most mentioned components of EQ are self-regard (22), followed by interpersonal relationships (21), problem solving (19), empathy (18), emotional self-awareness (16), assertiveness and impulse control (each 15) and social responsibility (14). This may state that women leaders are aware that self-regard lays an important foundation for their leadership, which provides them with an understanding and acceptance of their strengths and weaknesses, relating to their inner strength and weaknesses. Self-regard forms the basis for interpersonal relationships, problem solving and empathy in women leaders and women leaders are aware that it to be successful they need a balance view on their strengths and weaknesses. A combination of these EI components provides women leaders, according to their emic perspective, with the ability to work well and stay healthy, while supporting colleagues and students on an optimal level.

The least mentioned components on the EI scale related to self-actualisation. This might be related to various reasons, such as that women leaders are able to self-actualise on their jobs and therefore do not see a need to mention it because it is taken as a given. However, it might also relate to the fact that women leaders have got such a high work load and the demand of combining work and family that they might not prioritise self-actualisation in this context. Following with the least mentioned components are independence, stress tolerance, flexibility and happiness (rated with four statements each). This shows that women leaders need to improve their awareness of these aspects within their private and professional lives and explore the importance of these functions on a deeper level, which might relate to a strong experience of dependence with regard to decision-making 
and networking, low levels of stress tolerance, flexibility particularly with regard to the fact that they on the one hand often experience flexibility at HEIs and on the other hand this work-related flexibility is needed to plan and organise work and private life strictly to at least being able to encouraging both of them. Adequate, mutual feedback from women leaders could encourage the development of underrepresented aspects of EI.

\section{Limitations}

This study is limited because of the qualitative research approach, Dilthey's hermeneutics' clearly defined research paradigm, the small sample size, the very specific research context, the philosophical framework chosen, limited research methods and the sample criteria and methods. The findings cannot be generalised but could provide information to inform future research and practice.

\section{Recommendations for future research and implications for practice}

Future research should particularly focus on the relationship of EI in women leadership taking diversity markers such as age, race, culture, mother tongue and gender. Furthermore, applying aspects of EI to managing challenges in HEIs should be explored more deeply. Research should focus particularly on the interrelationship of EI in women leaders and their mental health and well-being. Theoretical responses to EI and its practical application at work should be explored more deeply through participant observation and action research.

This study follows the request of Singh (2010) to strengthen EI in women leaders, here particularly focusing on selfactualisation, independence, stress tolerance, flexibility and happiness and provide an environment that welcomes and fosters these qualities in women leaders. Based on the emphasised needs described in this study, Grant (2007) suggests that HEIs offer specific training programmes for women leaders. This research supports this idea by emphasising that attention needs to be particularly drawn to the less adhered EQ components.

\section{Acknowledgements}

We thank Higher Education Research Service South Africa (HERS-SA) for commissioning this research project and all the women who participated.

\section{Competing interests}

The authors declare that they have no financial or personal relationship(s) that may have inappropriately influenced them in writing this article.

\section{Authors' contributions}

S.S. was the project leader, and C.M. and R.O. wrote the article.

\section{References}

Anand, R., \& Suriyan, G.U. (2010). Emotional intelligence and its relationship with leadership practices. International Journal of Business Management, 5(2), 65-76.

Andries, A.M. (2009). Emotions management within organizations. Journal of Economic Applied Information, 15(2), 17-34.

Appelbaum, S.A. (1973). Psychological mindedness: Word, concept, and essence. International Journal of Psychoanalysis, 54, 35-46.

Bar-On, R. (1997). The emotional intelligence inventory (EQ-i): Technical manual. Toronto: Multi-Health Systems.

Bar-On, R. (2000). Emotional and social intelligence: Insights from the Emotiona Quotient Inventory, pp. 363-388, San Francisco: Jossey-Bass.

Bar-On, R. (2002). Bar-On emotional quotient inventory (EQ-I): Technical manual. Toronto: Multi-Health Systems.

Bar-On, R. (2006). The Bar-On model of emotional-social intelligence (ESI). Psicothema, $18,13-25$.

Booysen, L. (2007). Barriers to employment equity implementation and retention of blacks in management in South Africa. South African Journal of Labour Relations, 31(1), 47-71.

Boyd, R. (2016). The search for lasting peace: Critical perspectives on genderresponsive human security. (2nd ed). London: Routledge.

Cavazotte, F., Moreno, V., \& Hickmann, M. (2012). Effects of leader intelligence, personality and emotional intelligence on transformational leadership and managerial performance. The Leadership Quarterly, 23(3), 443-455. https://doi. org/10.1016/j.leaqua.2011.10.003

Chaudhry, A.A., \& Saif, M.I. (2012). Presence and potential of emotional intelligence (EI) in organizational settings. African Journal of Business Management, 6(20), $6117-6122$

Darkwah, A.K. (2007). Making Hay While the Sun Shines: Ghanaian female traders and their insertion in the Global Economy. In N. Gunewardena \& A. Kingsolver (Eds.), The gender of globalization: Women navigating cultural and economic marginalities (pp. 61-83). Oxford: James Currey.

Darwin, C. (1872/1965). The expression of the emotions in man and animals. Chicago, IL: University of Chicago Press.

Department of Labour. (1998). Employment Equity Act, No. 55 of 1998. Retrieved n.d., from http://www.labour.gov.za

Dilthey, W. (2002/1910). The formation of the historical world in the human sciences. In Wilhelm Dilthey selected works. Volume III. Princeton, NJ: Princeton University Press.

Dulewicz, V., \& Higgs, M. (2000). Emotional intelligence: A review and evaluation study. Journal of Managerial Psychology, 15(4), 341-372. https://doi.org/ $10.1108 / 02683940010330993$

Du Plessis, Y., \& Barkhuizen, N. (2012). Career path barriers experienced by women engineers. Paper presented at the 12th European Academy of Management Conference, Rotterdam, Netherlands. Retrieved October 16, 2014, from http:// www.optentia.co.za/publications.php

Du Toit, A.J. (2014). Emotional intelligence and leadership in a South African financial services institution. Unpublished master's dissertation, UNISA: University of South Africa, Pretoria, South Africa.

Du Toit, A.J., Viviers, R., \& Mayer, C.-H. (2016). Emotional intelligence and leadership in a South African financial service institution. South African Journal of Labour Relations, $40(2)$

Ellingson, L.L. (2013). Analysis and representation across the continuum. In N.K. Denzin \& Y.S. Lincoln (Eds.), Collecting and interpreting qualitative materials (4th edn.). London: Sage.

Faulkner, W. (2009). Doing gender in engineering workplace cultures. II. Gender in/ authenticity and the in/visibility paradox. Engineering Studies, 18(3), 169-189. https://doi.org/10.1080/19378620903225059

Goleman, D. (1998). Working with emotional intelligence. London: Bloomsbury Publishing.

Gouws, A. (2008). Obstacles for women in leadership positions: A case of South Africa. Signs: Journal of Women in Culture and Society, 34(1), 21-27.

Grant, A.M. (2007). Enhancing coaching skills and emotional intelligence through training. Individual Commercial Training, 39(5), 257-266. https://doi.org/ 10.1108/00197850710761945

Grigoriou, S., Vasiliki, Z., Tachias, F., Gilyana, M., \& Bougiesi, M. (2012). Emotiona intelligence, age and physical activity: Review of contemporary literature. Inquiries in Sport \& Physical Education, 10, 17-29.

Healey, J.F., \& O'Brian, E.T. (2015). Race, ethnicity, gender, \& class. The sociology of group conflict and change. (7th edn.). London: Sage.

Jonck, P., \& Swanepoel, E. (2015). Exploring the theoretical link between cultural and emotional intelligence: A system analysis for human resource management. South African Journal of Business Management, 46(4), 77-84.

Jonker, C.S. (2009). The effect of an emotional intelligence development programme on accountants. South African Journal of Human Resource Management, $7(1)$ 157-165.

Kafetsios, K., \& Zampetakis, L. (2008). Emotional intelligence and job satisfaction Testing the mediatory role of positive and negative affect at work. Personality and Individual Differences, 44(3), 710-720. https://doi.org/10.1016/j.paid. 2007.10.004 
Kelly, E.J., \& Kaminskiené, N. (2016). The importance of emotional intelligence in negotiation and mediation. International Comparative Jurisprudence, 2(1), 55-60. https://doi.org/10.1016/j.icj.2016.07.001

Kinnear, L. (2014). A critical analysis of the emerging models of power amongst South African women business leaders. Unpublished doctoral thesis, University of KwaZulu Natal (UKZN), Durban.

Lazovic, S. (2012). The role and importance of emotional intelligence in knowledge management. Paper presented at the 'Management, Knowledge and Learning International Conference', 20-22 June, Celje, Slovenia.

Lewis-Enright, K., Crafford, A., \& Crous, F. (2009). Towards a workplace conducive to the career advancement of women. South African Journal of Industrial Psychology 35(1), 9. https://doi.org/10.4102/sajip.v35i1.832

Lincoln, Y.S., \& Guba, E.G. (1985). Naturalistic inquiry. Thousand Oaks, CA: Sage.

Mabokela, R.O., \& Mawila, K.F.N. (2004). The impact of race, gender, and culture in South African Higher Education. Comparative Education Review, 48(4), Special Issue on Global Trends in Comparative Research on Gender and Education Issue on Global Trends in Comparative Research on Gender and Education
Guest Editors: N'Dri Assié-Lumumba and Margaret Sutton (November 2004), Guest Editors:
pp. 396-416.

Martin, P., \& Barnard, A. (2013). The experience of women in male-dominated occupations: A constructivist grounded theory inquiry. SA Journal of Industrial occupations: A constructivist grounded theory inquiry. SA Journa
Psychology, 39(2), 12. https://doi.org/10.4102/sajip.v39i2.1099

Mayer, C-H. (2008). Managing conflict across cultures, values and identities. Münster, Germany: Waxmann.

Mayer, C-H. (2011). The meaning of sense of coherence in transcultural management Münster, Germany: Waxmann.

Mayer, C-H., \& Barnard, A. (2015). Balancing the scales of gender in contemporary South Africa. In S. Safdar \& N. Kosakowska-Berezecka (Eds.), Psychology of gender through the lens of culture. Theories and applications (pp. 327-352). Cham: Springer.

Mayer, C-H., Surtee, S., \& Barnard, A. (2015). Women leaders in higher education: A psycho-spiritual perspective. South African Journal of Psychology, 45(1), 102-115. https://doi.org/10.1177/0081246314548869

Mayer, C-H., \& Van Zyl, L.E. (2013). Perspectives of female leaders on sense of coherence and mental health in an engineering environment. SA Journal of Industrial Psychology/SA Tydskrif vir Bedryfsielkunde, 39(2), Art. \#1097, 1-11. https://doi.org/10.4102/sajip.v39i2.1097

McCallum, M., \& Piper, W.E. (2000). Psychological mindedness and emotional intelligence. In R. Bar-On \& J.D.A. Parker (Eds.), The handbook of emotional intelligence. In R. Bar-On \& J.D.A. Parker (Eds.), The handbook of emotional intelligence: Theory, development, assessment, and the application at hom
school and in the workplace (pp. 118-135). San Francisco, CA: Jossey-Bass Inc.

Mostert, K. (2009). The balance between work and home: The relationship between work and home demands and ill health of employed females. South African Journal of Industrial Psychology, 35(1), Art.\#743, 1-8. https://doi.org/sajip. v35i1.743

Oosthuizen, R.M., \& Naidoo, V. (2010). Attitudes towards and experience of employment equity. SA Journal of Industrial Psychology/SA Tydskrif vir Bedryfsielkunde, 36(1), Art. \#836, 1-9. https://doi.org/10.4102/sajip.v36i1.836

Patton, M.Q. (2002). Qualitative evaluation and research methods (3rd ed.). Thousand Oaks, CA: Sage.

Pillay, M., Viviers, R., \& Mayer, C. (2013). The relationship between emotional intelligence and leadership styles in the South African petrochemical industry. $S A$ Journal of Industrial Psychology/SA Tydskrif vir Bedryfsielkunde, 39(1), Art. \#1109, 1-12. https://doi.org/10.4102/sajip.v39i1.1109

Poggenpoel, M. (1998). Data analysis in qualitative research. In A.S. de Vos (Ed.), Research on grass roots: A primer for the caring professions (pp. 334-354).
Pretoria: Van Schaik.

Puttick, K. (2012), First year students' narratives of 'race' and racism in post-apartheid South Africa. Unpublished master's thesis, University of Witwatersrand, Johannesburg.

Rahim, S.H., \& Malik, M.I. (2010). Emotional intelligence and organizational performance: A case study of banking sector of Pakistan. International Journal of performance: A case study of banking sect
Business Management, 5(10), 191-197.
Ramesar, S., Koortzen, P., \& Oosthuizen, R.M. (2009). The relationship between emotional intelligence and stress management. South African Journal of Industrial Psychology, 35(1), 17-21.

Ratner, C. (2002). Subjectivity and objectivity in qualitative methodology. Forum Qualitative Social Research, 3(3). Retrieved from http://www.qualitativeresearch.net/index.php/fqs/article/view/829/1800

Salovey, P. \& Mayer, J.D. (1990). Emotional intelligence. Imagination, Cognition, and Personality, 9, 185-211.

Sifneos, P.E. (1967). Clinical observations on some patients suffering from a variety of psychosomatic diseases. Acta Medicina Psychosomatica, 21, 133-136. https:// doi.org/10.1159/000287665

Singh, K. (2010). Developing human capital by linking emotional intelligence with personal competencies in Indian business organizations. International Journal of Business Science and Applied Management, 5(2), 30-42.

Sinha, C., \& Kumar, H. (2016). Relationship between emotional intelligence, work attitude \& outcomes: Examination of Indian middle-managerial level employees. Journal of Organizational Psychology, 16(1), 118-125.

Salovey, P., \& Mayer, J.D. (1990). Emotional intelligence. Imagination, Cognition and Personality, 9, 185-211. https://doi.org/10.2190/DUGG-P24E-52WK-6CDG

Stein, S.J., \& Book, H.E. (2006). The EQ edge: Emotional intelligence and your success (3rd edn.). (Revised and updated). Mississauga, ON: Wiley.

Stein, S.J., Papadogiannis, P., Yip, J.A., \& Sitarenios, G. (2009). Emotional intelligence of leaders: A profile of top executives. Journal of Leadership Organizational Development, 30(1), 87-101. https://doi.org/10.1108/01437730910927115

Stuart, A., \& Paquet, A. (2001). Emotional intelligence as a determinant of leadership potential. Journal of Industrial Psychology, 27(3), 30-34. https://doi.org/10.4102/ sajip.v27i3.21

Teferra, D., \& Altbach, P.G. (2004). African Higher Education: Challenges for the 21st century. Higher Education, 47(1), 21-50. https://doi.org/10.1023/B:HIGH. 0000009822.49980 .30

Terre Blanche, M., Durrheim, K., \& Kelly, K. (2006). First steps in qualitative data analysis. In M. Terre Blanche, K. Durrheim, \& D. Painter (Eds.), Research in practice. Applied methods for the social sciences (pp. 321-344). Cape Town: University of Cape Town.

Thorndike, E.L. (1920). Intelligence and its uses. Harper's Magazine, 140, 227-235.

Vaismoradi, M., Jones, J., Turunen, H., \& Snelgrove, S. (2016). Theme development in qualitative content analysis and thematic analysis. Journal of Nursing Education and Practice, 6(5), 100. https://doi.org/10.5430/jnep.v6n5p100

Vaismoradi, M., Turunen, H., \& Bondas, T. (2013). Content analysis and thematic analysis: Implications for conducting a qualitative descriptive study. Nursing Health Science, 15(3), 398-405. https://doi.org/10.1111/nhs.12048

Van der Riet, M., \& Durrheim, K. (2008). Putting design into practice: Writing and evaluating research proposals. In M.T. Terre Blanche, K. Durrheim, \& D. Painter (Eds.), Research in practice. Applied methods for the social sciences (pp. 80-112). Cape Town: University of Cape Town.

Van Wyk, M. (2012). Women leaders, personal leadership and challenges. Unpublished master's thesis, University of Johannesburg, Johannesburg.

Wechsler, D. (1940). Nonintellective factors in general intelligence. Psychological Bulletin, 37, 444-445.

Wechsler, D. (1943). Nonintellective factors in general intelligence. Journal of Abnormal Social Psychology, 38, 100-104. https://doi.org/10.1037/h0060613

Wing, A.K., \& De Carvalho, E.P. (1995). Black South African women: Toward equal rights. Harvard Human Rights, 57, 47-100.

Yamani, N., Shahabi, M., \& Haghani, F. (2014). The relationship between emotiona intelligence and job stress in the faculty of medicine in Isfahan University of Medical Sciences. Journal of Advance Medicine Education, 2(1), 20-26.

Yin, R.K. (2009). Case study research: Design and methods. (4th ed.). London: Sage Publications. 